\title{
Physiological Activities of Policosanol Extracted from Sugarcane Wax
}

\author{
Yeon-su Jang', Dae-eun Kim ${ }^{1}$, Eunyoung Han ${ }^{1,2}$, and Joohee Jung ${ }^{1,2, *}$ \\ ${ }^{I}$ College of Pharmacy, Duksung Women's University, Seoul 01369 Korea \\ ${ }^{2}$ Duksung Innovative Drug Center, Duksung Women's University, Seoul 01369 Korea
}

\begin{abstract}
Policosanol extracted from sugarcane wax is a generic term used for total fatty alcohols obtained from esterification of fatty acids. It has been approved as a health functional food by the Ministry of Food and Drug Safety of Korea in 2006. Policosanol is well-known to aid in lowering blood cholesterol level. Recently, several studies have reported the physiological activities of policosanol, such as anti-inflammatory effects, antioxidant effects, and lowering of the incidence of ageing-related diseases, for example, hypertension, stroke, among others. This review describes the physiological activities of policosanol and its applications in the field of health functional foods.
\end{abstract}

Keywords - policosanol, health functional food, sugarcane wax, physiological activities

\section{Introduction}

Policosanol is a generic term used for aliphatic alcohols which belong to 1-tetracosanol (C-24), 1-hexacosanol (C26), 1-heptacosanol (C-27), 1-octacosanol (C-28), 1-nonacosanol (C-29), 1-triacontanol (C-30), 1-dotriacontanol (C-32), and 1-tetratriacontano (C-34) class. Policosanol was first obtained by extraction of sugarcane wax by Dalmer Laboratories of Cuba. ${ }^{1}$ It is also obtained from bee wax, grains, fruits, nuts, among other sources. However, its composition varies depending on the source. Studies have reported contradictory physiological activities of policosanol. Thus, only policosanol from sugarcane wax has been approved by the Korea Food and Drug Administration as a health functional food with cholesterol-lowing activity. High cholesterol level is well known to cause hypertension, cardiovascular diseases, and so on. Thus, physiological activities of policosanol for cholesterol-related diseases have been studied. Recently, several studies have reported that policosanol has antiinflammatory effects, antioxidant effects, and lowering of the incidence of cardiovascular diseases. Here, this review summarized various physiological activities of policosanol and its known mechanism until now and discussed the additional applicable function of policosanol as a health functional food.

\footnotetext{
*Author for correspondence

Joohee Jung, College of Pharmacy, Duksung Women's University,

33, Samyangro 144-gil, Dobong-gu, Seoul 01369, Korea

Tel: +82-2-901-8731; E-mail: joohee@duksung.ac.kr
}

\section{Physiological activities of policosanol}

Improvement in blood lipid levels - Blood lipids refer to cholesterol and triglyceride (TG). When the blood level of lipoprotein is abnormally high, it is called hyperlipidemia, which is a risk factor for different cardiovascular diseases, for example, hypertension and myocardial infarction. In addition, it is also known that insulin resistance can lead to diabetes. Hyperlipidemia refers to hypercholesterolemia, i.e. a blood cholesterol level of $\geq 240 \mathrm{mg} / \mathrm{dL}$, and hypertriglyceridemia signifies a serum TG level of $\geq 200 \mathrm{mg} / \mathrm{dL}$. $^{2}$

Policosanol, extracted from sugarcane wax, was first approved in Cuba in 1991 as an effective agent to reduce blood lipid levels. It has been since approved as a cholesterol-lowering health supplement in over 25 countries. ${ }^{3}$ In Korea, it has been approved by the Korea Food and Drug Administration as a health functional food in 2006 because of its ability to improve blood TG level.

Policosanol has been found to inhibit cholesterol synthesis by suppressing the expression of HMG-CoA (3hydroxy-3-methyl-glutaryl coenzyme reductase) reductase by activating AMP kinase in rat liver cancer cells and HepG2 cell lines. ${ }^{4-6}$ Furthermore, cholesterol-lowing effect of policosanol was reported in various animal models. In male Wistar rats, $500 \mathrm{mg}$ of policosanol administered orally for 4 weeks inhibited the synthesis of cholesterol by affecting HMG-CoA reductase indirectly. ${ }^{7}$ In New Zealand rabbits, $50 \mathrm{mg} / \mathrm{kg}$ of policosanol suppressed lowdensity lipoprotein-cholesterol (LDL-C) and synthesis of 
TG from acetate at liver cells. ${ }^{8,9}$ In beagles, $25 \mathrm{mg} / \mathrm{kg}$ of policosanol decreased total cholesterol (TC) and LDL-C levels. ${ }^{10}$ In Macaca arctoides monkey, cholesterol-lowing effect of policosanol was increased depending on treatment of periods and dose. ${ }^{11}$ These results indicated that policosanol improved the blood lipid level. In human volunteers having normal or boarderline TC level, policosanol $(5$ or $10 \mathrm{mg}$ ) has been found to significantly reduce LDL-C, TC, and TG levels, and increase highdensity lipoprotein- cholesterol (HDL-C) level. ${ }^{12-14} \mathrm{~A}$ significant reduction in TC and LDL-C levels was found in all studies, but TG level did not show any significant change in several studies. ${ }^{15,16}$ The results are considered to be influenced by different sources or the content ratio of policosanol. For example, policosanol extracted from wheat germ has a similar composition to that obtained from sugarcane wax, but ingestion of $20 \mathrm{mg}$ /day of policosanol obtained from wheat germ did not show any lipid-lowering effects. ${ }^{17}$

It was reported that policosanol $(10 \mathrm{mg})$ could be alternative to simvastatin or pravastatin which are HMGCoA reductase inhibitors. ${ }^{18}$ In addition, the combination simvastatin and policosanol ${ }^{19}$ or fenofibrate and policosanol $^{20}$ enhanced the reduction of TC and LDL-C levels in dyslipidemia more than simvastatin or fenofibrate monotherapy. These results suggest that policosanol enhances the therapeutic efficacy of simvastatin or fenofibrate through multiple pathways (the reduction of TG synthesis and the inhibition of HMG-CoA reductase expression) different from HMG-CoA reductase inhibitors.

LDL receptor plays a major role in regulating blood cholesterol level through binding to LDL-C. Proprotein convertase subtilisin/kexin type 9 (PCSK9) enzyme ${ }^{21,22}$ degrades LDL receptor. ${ }^{23} \mathrm{~A}$ high dose of atorvastatin, one of the statins, was known to increase PCSK9 enzyme level. ${ }^{21,22}$ Thus, some patients are limited to use atorvastatin. However, the combination of atorvastatin and policosanol attenuates the adverse effects of atorvastatin because policosanol reduced PCSK9 level. ${ }^{24}$ These results indicate that policosanol could help in overcoming the limitations of atorvastatin.

Improvement in hypertension-Hypertension is defined as a systolic blood pressure of $\geq 140 \mathrm{mmHg}$ or diastolic blood pressure of $\geq 90 \mathrm{mmHg}$. The incidence rate of cardiovascular disease increases unless hypertension including pre-hypertension $(\geq 120$ or $80 \mathrm{mmHg})$ is controlled. ${ }^{25}$ An increase in TG and LDL-C level, reduction in HDL-C level, and oxidative stress trigger hypertension. Thus, policosanol inhibiting high TC, TG, and LDL-C levels is considered to regulate blood pressure. The results reported that policosanol dose-dependently decreased systolic and diastolic blood pressure in spontaneously hypertensive rats. ${ }^{26}$ When healthy volunteers with prehypertension were administered policosanol for a long time, TC and LDL-C levels were reduced and HDL-C level increased. ${ }^{26,27}$ Further, peripheral blood pressure, as well as aortic pressure, simultaneously decreased. ${ }^{26}$ These results indicated that policosanol could be utilized for improving the symptoms of hypertension by controlling blood lipid level.

Antioxidant activities-Lipid oxidation leads to hypertension and cardiovascular diseases through the formation of plaques within blood vessels. Policosanol protects against peroxidation of lipids. The antioxidant activity of policosanol was demonstrated in rat liver microsomes, ${ }^{28}$ however, the same was not observed against LDL in hamsters and human. ${ }^{29}$ Nevertheless, the protective effects of policosanol against lipid peroxidation were investigated in dyslipidemic ${ }^{30}$ and type 2 diabetesinduced dyslipidemic patient. ${ }^{31}$ The antioxidant effects of policosanol including that present in milk thistle were determined by radical scavenging analysis using 2,2diphenyl-1-picrylhydrazyl (DPPH) and 2,2'-azino-bis (3ethyl- benzothiazoline-6-sulfonic acid) (ABTS). The quantity of policosanol was associated with its antioxidant activities. $^{32}$

Improvement in hyperglycemia - Diabetes is induced by dyslipidemia as well as hyperglycemia, and thus, the reduction of LDL-C level is important in order to prevent hyperglycemia. Diabetic hyperlipidemic rats administered policosanol, which could regulate blood lipid level, were found to have low blood glucose levels. ${ }^{33,34}$ Additionally, policosanol obtained from rice bran extract was also reported to improve glucose tolerance indicating its ability to protect against diabetes. ${ }^{35}$

Prevention of cardiovascular diseases - The foam cells engulfed by oxidized LDL-C in blood vessels can cause atherosclerosis by accumulating within the inner wall of blood vessels. Policosanol reduces the density and number of foam cells in diabetic hyperlipidemic rats and cures lesions. ${ }^{34}$ Additionally, policosanol inhibits tumor necrosis factor- $\alpha$ (TNF- $\alpha$ ), a mediator of inflammation, and vascular calcification. ${ }^{34}$ PCSK9, which is associated with the metabolism of cholesterol and fatty acids, is known as a factor of vascular calcification. Policosanol mitigates vascular calcification via inhibition of PCSK9, and a combination of policosanol and pentoxifylline, an enhancer of blood circulation, improves its therapeutic efficacy. ${ }^{36}$ Furthermore, policosanol decreases blood lipid levels in Wistar rat model of atherosclerosis. ${ }^{37}$ 
Policosanol (5 50 mg/day) obtained from sugarcane decreased platelet aggregation in both healthy and dyslipidemia groups, suggesting inhibition of thrombosis. ${ }^{38,39}$ The inhibitory effects on platelet aggregation were also shown in rat administered policosanol extracted from rice. ${ }^{40,41}$ The inhibitory effects of policosanol on platelet aggregation could be applied in intermittent claudication. Policosanol intake for 10 weeks improved walking distance. ${ }^{42}$ These results might be attributed to policosanol's anti-platelet activity, and it causes a reduction of LDL-C and increases HDL-C level.

Stroke is associated with ischemia which is caused by problems in the flow of blood through blood vessels. Policosanol (100 and $200 \mathrm{mg} / \mathrm{kg}$ ) significantly reduced symptoms, frequency, tissue damage, and plasma oxidation markers in cerebral ischemia-induced ischemiareperfusion injury in gerbil rats. A high dose $(200 \mathrm{mg} / \mathrm{kg})$ of policosanol was most effective, and policosanol reduced the plasma oxidation factors as compared to that by atorvastatin. ${ }^{43}$ Statins and aspirin as antiplatelet drugs are used to prevent secondary ischemic stroke. TC reduction by policosanol correlates with the improvement in nerve functions. In ischemic stroke patients treated with policosanol, there is a correlation between the decrease in TC level and improvement in nerve functions. ${ }^{44} \mathrm{~A}$ combination of policosanol and aspirin improves symptoms in patients with ischemic stroke. ${ }^{45}$ In patients treated with policosanol, the modified Rankin Scale (mRS) score, which is used to evaluate the daily activities in stroke patients, was reduced from $2 \sim 4$ to $\leq 1$, and the Barthel index, which is used to assess performance status, was significantly increased. ${ }^{46,47}$ Furthermore, the vascular oxidation factors were significantly reduced. ${ }^{48}$ In patients with hypertension who had ischemic stroke without cardiovascular disease, treatment with a combination of policosanol and aspirin significantly lowered the mRS score compared to the values in the group treated with aspirin only. ${ }^{49}$

Prevention of aging-related diseases - By increasing HDL-C level, policosanol plays a role in the prevention of aging-related diseases, such as Alzheimer's disease, cardiovascular diseases, and diabetes, which are caused by a change in HDL-C level. Furthermore, HDL-C function was improved by inhibition of cholesteryl ester transfer protein (CETP). Policosanol-containing HDL inhibited CETP activities and scavenged reactive oxygen species $(\mathrm{ROS})^{50}$ and upregulated tissue-regeneration activities in glioma cells ${ }^{51}$ and zebrafish. ${ }^{50}$

In addition, policosanol, which inhibits CETP activities, decreases the progression of hepatic steatosis. ${ }^{50}$ Hexacosanol,

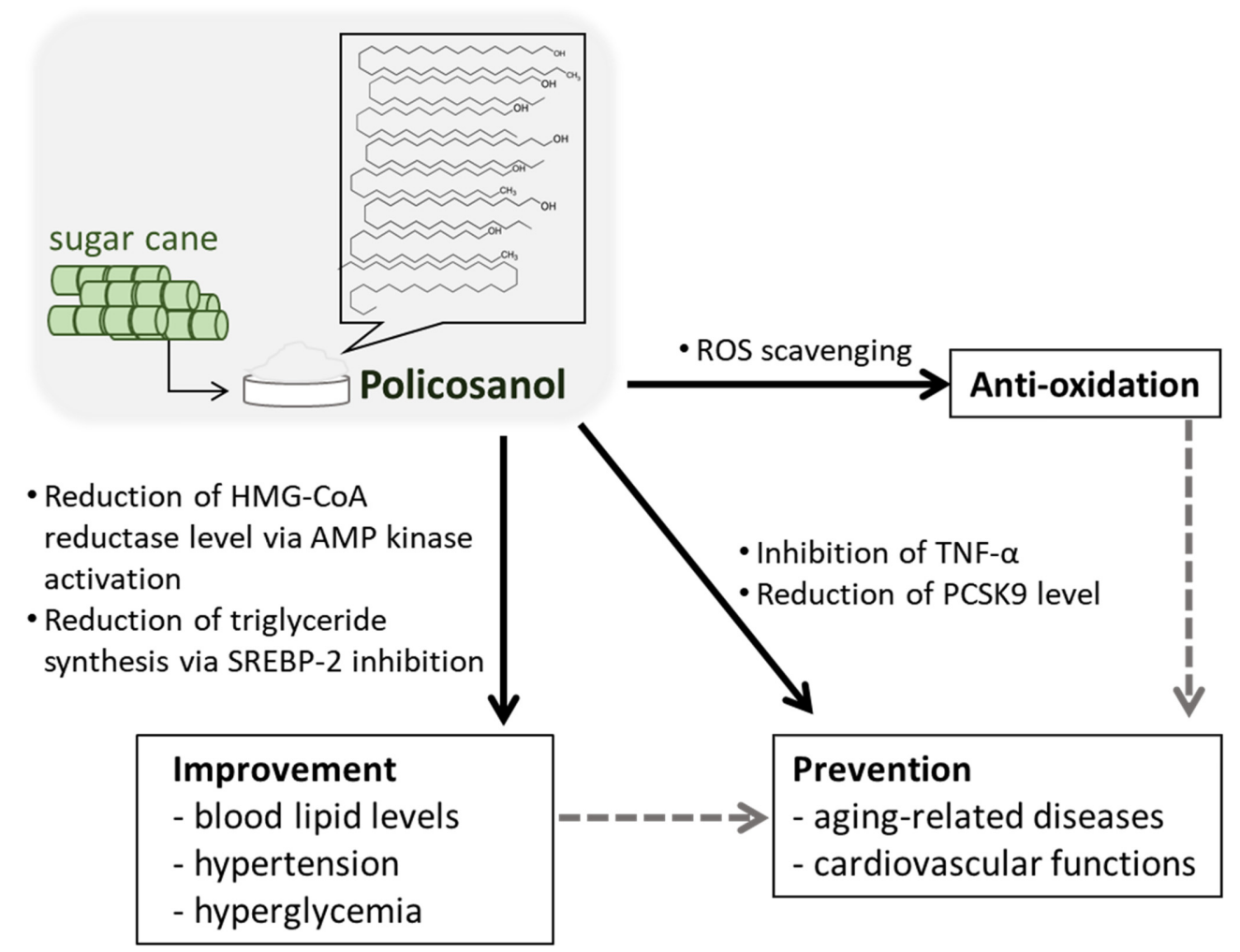

Fig. 1. Physiological activities and mechanism of policosanol. 
Table 1. Summary of policosanol's physiological activities

\begin{tabular}{ll}
\hline \hline \multicolumn{1}{c}{ Physiological activities } & \multicolumn{1}{c}{ Biomarker } \\
\hline \multirow{3}{*}{ Improvement of dyslipidemia } & Decrease of total cholesterol and LDL-cholesterol \\
& Increase of HDL-cholesterol \\
& Decrease of triglyceride \\
& Decrease of total cholesterol and LDL-cholesterol \\
& Increase of HDL-cholesterol \\
Improvement of hypertension & Antioxidant activity \\
& Decrease of systolic and diastolic blood pressure in rat \\
& Simultaneous decrease of artery and peripheral blood pressure in human \\
& Radical scavenging by DPPH, ABTS assay \\
Antioxidant activity & Protection of lipid peroxidation \\
& Reduction of the blood glucose \\
Prevention of diabetes & Decrease of LDL-cholesterol \\
& Inhibition of TNF- $\alpha$ and PCSK9 \\
& Inhibition of vascular calcification \\
Prevention of cardiovascular diseases & Decrease of platelet aggregation \\
& Decrese of modified Rankin Scale \\
& Increase of Barthel index \\
Increase of walking distance on treadmill \\
Increase of HDL/apoA-I and enhancement of HDL fuction \\
Prevention of ageing-related disease & Decrease of blood pressure and CETP activity \\
& Inhibition of HMG-CoA reductase by AMPK activation \\
& Induce of autophagy \\
& Inhibition of SREBP-2 activity \\
\hline
\end{tabular}

one of the policosanol components, improves the symptoms of fatty liver through inhibition of HMG-CoA reductase by activation of AMP kinase, induction of autophagy, reduction of lipid accumulation in the liver, and inhibition of sterol regulatory element-binding protein 2 (SREBP-2) which is known as a key transcription factor of cholesterol synthesis. ${ }^{52}$

\section{Conclusion}

Dyslipidemia is defined as an abnormal blood lipid level including cholesterol and triglyceride (TG). The progression of dyslipidemia is related to the incidence of hypertension, diabetes and cardiovascular diseases. These diseases are health-threatening and contribute to the top five causes of death in Korea. ${ }^{53}$ Policosanol decreases TC, TG, and LDL-C levels and increases HDL-C level through inhibition of HMG-CoA reductase expression level and activity of SREBP-2, thereby improving blood lipid levels. These activities of policosanol prevent or improve the symptoms of various chronic diseases. In addition, the antioxidant activities and inhibition of TNF- $\alpha$ activities are the mechanism of policosanol to prevent cardiovascular diseases as a health functional food (Fig. 1). In Table 1, we have summarized the physiological activities of policosanol and its applications. However, most of the previous studies have used policosanol extracted from sugarcane wax, and the degree of physiological activities of policosanol extracted from other sources, such as malt and rice bran, varies. Policosanol is a generic term used for aliphatic alcohols and its composition depends on the sources. Therefore, studies on aliphatic alcohol content and other contents of policosanol should be continued.

\section{Acknowledgment}

This research was funded by Priority Research Centers Program through the NRF funded by the Ministry of Education, Science and Technology (2016R1A6A1A0300 7648).

\section{References}

1. Marinangeli, C. P.; Kassis, A. N.; Jain, D.; Ebine, N.; Cunnane, S. C.; Jones, P. J. Br. J. Nutr. 2007, 97, 381-388.

2. Committee for the Korean Guidelines for the Management of Dyslipidemia. Korean Circ. J. 2016, 46, 275-306.

3. Marinangeli, C. P.; Jones, P. J.; Kassis, A. N.; Eskin, M. N. Crit. Rev. Food Sci. Nutr. 2010, 50, 259-267.

4. Liao, F.; Chen, W. Hubei Agric. Sci. 2013, 52, 1125-1127.

5. Singh, D. K.; Li, L.; Porter, T. D. J. Pharmacol. Exp. Ther. 2006, 318, 1020-1026.

6. Banerjee, S.; Ghoshal, S.; Porter, T. D. Lipids 2011, 46, 311-321.

7. Menendez, R.; Amor, A. M.; Gonzalez, R. M.; Fraga, V.; Mas, R. Biol. Res. 1996, 29, 253-257.

8. Menéndez, R.; Arruzazabala, L.; Más, R.; Del Rio, A.; Amor. A. M.; González, R. M.; Carbajal, D.; Fraga, V.; Molina, V.; Illnait, J. Br. J. Nutr. 
1997, 77, 923-932.

9. Arruzazabala, M. L.; Carbajal, D.; Mas, R.; Molina, V.; Valdes, S.; Laguna, A., Biol. Res., 1994, 27, 205-208.

10. Arruzazabala, M. L.; Carbajal, D.; Mas, R.; Castano, G.; Sotolongo, R.; Mesa, R. Rev. CENIC Cien. Biol. 1991, 22, 60-61.

11. Rodriguez-Echenique, C.; Mesa, R.; Mas, R.; Noa, M.; Menendez, R.; Gonzalez, R. M.; Amor, A. M.; Fraga, V.; Sotolongo, V.; Laguna, A. Food Chem. Toxicol. 1994, 32, 565-575.

12. Hernandez, F.; Illnait, J.; Mas, R.; Castano, G.; Fernández, L.; Gonzalez, M.; Cordovi, N.; Fernandez, J. C. Curr. Ther. Res. Clin. Exp. 1992, 51, 568-575.

13. Castano, G.; Mas, R.; Fernandez, J.; Lopez, E.; Illnait, J.; Fernandez, L.; Mesa, M. Curr. Ther. Res. Clin. Exp. 2003, 64, 522-537.

14. Lopez, E.; Illnait, J.; Fernandez, J. C.; Fernandez, L.; Gamez, R.; Mesa, M.; Mendoza, S.; Mas, R.; Ruiz, D.; Jardines, Y. Rev. CRNIC Cien. Biol. 2010, 41, 31-37.

15. Castano, G.; Mas, R.; Fernandez, L.; Illnait, J.; Hernandez, E.; Fernandez, J.; Gamez, R.; Gutierrez, C.; Alvarez, E. Curr. Ther. Res. 2002, 63, 286-303.

16. Illnait, J.; López, E.; Fernández, L.; Mas, R.; Gamez, R.; Mesa, M.; Mendoza, S.; Fernández, J. C. Int. J. Pharm. Sci. Rev. Res. 2013, 22, 303309 .

17. Lin, Y.; Rudrum, M.; van der Wielen, R. P.; Trautwein, E. A.; McNeill, G.; Sierksma, A.; Meijer, G. W. Metabolism 2004, 53, 13091314.

18. Gouni-Berthold, I.; Berthold, H. K. Am. Heart J. 2002, 143, 356365 .

19. Tang, M.; Wu, S. Z.; Gong, X. Zhonghua Xin Xue Guan Bing Za Zhi 2013, 41, 488-492.

20. Wang, H. Y.; Jiao, Q. P.; Chen, S. Y.; Sheng, J.; Jiang, H.; Lu, J.; Zheng, S. B.; Fang, N. Y. Am. J. Med. Sci. 2018, 356, 254-261.

21. Careskey, H. E.; Davis, R. A.; Alborn, W. E.; Troutt, J. S.; Cao, G.; Konrad, R. J. J. Lipid Res. 2008, 49, 394-398.

22. Welder, G.; Zineh, I.; Pacanowski, M. A.; Troutt, J. S.; Cao, G.; Konrad, R. J. J. Lipid Res. 2010, 51, 2714-2721.

23. Mousavi, S. A.; Berge, K. E.; Leren, T. P. J. Intern. Med. 2009, 266, 507-519.

24. Guo, Y. L.; Xu, R. X.; Zhu, C. G.; Wu, N. Q.; Cui, Z. P.; Li, J. J.

Evid. Based Complement. Alternat. Med. 2014, 2014, 926087.

25. Lee, H. Y. J. Korean Med. Assoc. 2018, 6, 485-492.

26. Kim, S. J.; Yadav, D.; Park, H. J.; Kim, J. R.; Cho, K. H. Front. Physiol. 2018, 9, 412.

27. Cho, K. H.; Kim, S. J.; Yadav, D.; Kim, J. Y.; Kim, J. R. Oxid. Med. Cell. Longev. 2018, 2018, 4809525.

28. Fraga, V.; Menendez, R.; Amor, A. M.; Gonzalez, R. M.; Jimenez, S.; Mas, R. Arch. Med. Res. 1997, 28, 355-360.

29. Ng, C. H.; Leung, K. Y.; Huang, Y.; Chen, Z. Y. J. Agric. Food Chem. 2005, 53, 6289-6293.

30. Cicero, A. F.; Colletti, A. Phytomedicine 2016, 23, 1113-1118.

31. Castano, G.; Menendez, R.; Mas, R.; Amor, A.; Fernandez, J. L.; Gonzalez, R. L.; Lezcay, M.; Alvarez, E. Int. J. Clin. Pharmacol. Res. 2002, 22, 89-99.

32. Harrabi, S.; Ferchichi, A.; Bacheli, A.; Fellah, H. Lipids Health Dis. 2018, 17, 82 .

33. Castano, G.; Fernandez, L.; Mas, R.; Illnait, J.; Mesa, M.; Fernandez,
J. C. Clin. Drug Investig. 2003, 23, 639-650.

34. Elseweidy, M. M.; Zein, N.; Aldhamy, S. E.; Elsawy, M. M.; Saeid, S. A. Exp. Biol. Med. 2016, 241, 1943-1949.

35. Kaup, R. M.; Khayyal, M. T.; Verspohl, E. J. Phytother. Res. 2013, 27, 264-271.

36. Elseweidy, M. M.; Mohamed, H. E.; Elrashidy, R. A.; Atteia, H. H.; Elnagar, G. M. J. Cardiovasc. Pharmacol. Ther. 2018, 23, 551-560.

37. Noa, M.; Mas, R.; de la Rosa, M. C.; Magraner, J. J. Pharm. Pharmacol. 1995, 47, 289-291.

38. Carbajal, D.; Arruzazabala, M. L.; Valdes, S.; Mas, R. Prostaglandins, Leukot. Essent. Fatty Acids 1998, 58, 61-64.

39. Arruzazabala, M. L.; Mas, R.; Molina, V.; Carbajal, D.; Mendoza, S.; Fernandez, L.; Valdes, S. Int. J. Tissue React. 1998, 20, 119-124.

40. Wong, W. T.; Ismail, M.; Tohit, E. R.; Abdullah, R.; Zhang, Y. D. Evid. Based Complement. Alternat. Med. 2016, 2016, 7343942.

41. Wong, W. T.; Ismail, M.; Imam, M. U.; Zhang, Y. D. BMC Complement. Altern. Med. 2016, 16, 252.

42. Illnait, J.; Castano, G.; Alvarez, E.; Fernandez, L.; Mas, R.; Mendoza, S.; Gamez, R. Angiology 2008, 59, 269-277.

43. Molina, V.; Ravelo, Y.; Noa, M.; Mas, R.; Perez, Y.; Oyarzabal, A.; Mendoza, N.; Valle, M.; Jimenez, S.; Sanchez, J. Indian J. Pharm. Sci. 2013, 75, 635-641.

44. Ortega, L. L.; Sanchez, J.; Mas, R.; Fernandez, L.; Mendoza, S.; Gamez, R.; Fernandez, J. C.; Illnait, J.; Alvarez, E. J. Med. Food 2006, 9, 378-385.

45. Sánchez, J.; Fernández, L. Illnait, J.; de Lourdes Arruzazabala, M.; Molina, V.; Mas, R.; Mendoza, S. Carbajal, D. Mesa, M.; Fernández, J. IOSR J. Pharm. 2012, 2, 14-24.

46. Sanchez, J.; Illnait, J.; Mas, R.; Mendoza, S.; Fernandez, L.; Mesa, M.; Vega, H.; Fernandez, J.; Reyes, P.; Ruiz, D. Rev. Neurol. 2017, 64, 153-161.

47. Sánchez, J.; Illnait, J.; Mas, R.; Mendoza, S.; Vega, H.; Fernández, L.; Mesa, M.; Fernández, J.; Reyes, P.; Ruiz, D. Int. J. Pharm. Sci. Rev. Res. 2016, 37, 7-14.

48. Sanchez, J.; Illnait, J.; Mas, R.; Perez, Y.; Mendoza, S.; Cabrera, L.; Fernandez, L.; Mesa, M.; Fernandez, J.; Oyarzabal, A.; Molona, V.; Reyes, P. IOSR J. Pham. 2013, 3, 31-40.

49. Sanchez-Lopez, J.; Fernandez-Travieso, J. C.; Illnait-Ferrer, J.; Fernandez-Dorta, L.; Mendoza-Castano, S.; Mas-Ferreiro, R.; MesaAngarica, M.; Reyes-Suarez, P. Rev. de Neuro. 2018, 67, 331-338.

50. Lee, E. Y.; Yoo, J. A.; Lim, S. M.; Cho, K. H. Rejuvenation Res. 2016, 19, 149-158.

51. Lim, S. M.; Yoo, J. A.; Lee, E. Y.; Cho, K. H. Rejuvenation Res. 2016, 19, 59-70.

52. Lee, J. H.; Jia, Y.; Thach, T. T.; Han, Y.; Kim, B.; Wu, C.; Kim, Y.; Seo, W. D.; Lee, S. J. Nutr. Res. 2017, 43, 89-99.

53. Lim, D.; Ha, M.; Song, I. J. Korean Med. Sci. 2014, 29, 1597-1603.

Received September 17, 2019

Revised November 12, 2019

Accepted November 24, 2019 